SHORT AND SWEET

\title{
Nonphysical visual objects generated by colour spreading are expected to cast shadows
}

\section{Roberto Casati ${ }^{1}$, Roy Sorensen ${ }^{2}$}

1 Institut Jean Nicod, CNRS-EHESS-ENS, 29 rue d'UIm, 75005 Paris, France; e-mail: casati@ehess.fr;

${ }^{2}$ Department of Philosophy, Washington University St Louis, St Louis, MO 63130, USA

Received 18 October 2012, in revised form 21 October 2012

Abstract. Purely visual objects created by colour spreading are expected to behave like any other physical object. In particular, they are expected to block light and to cast shadows.

Keywords: shadows, colour spreading, nonphysical objects

Consider figure 1.

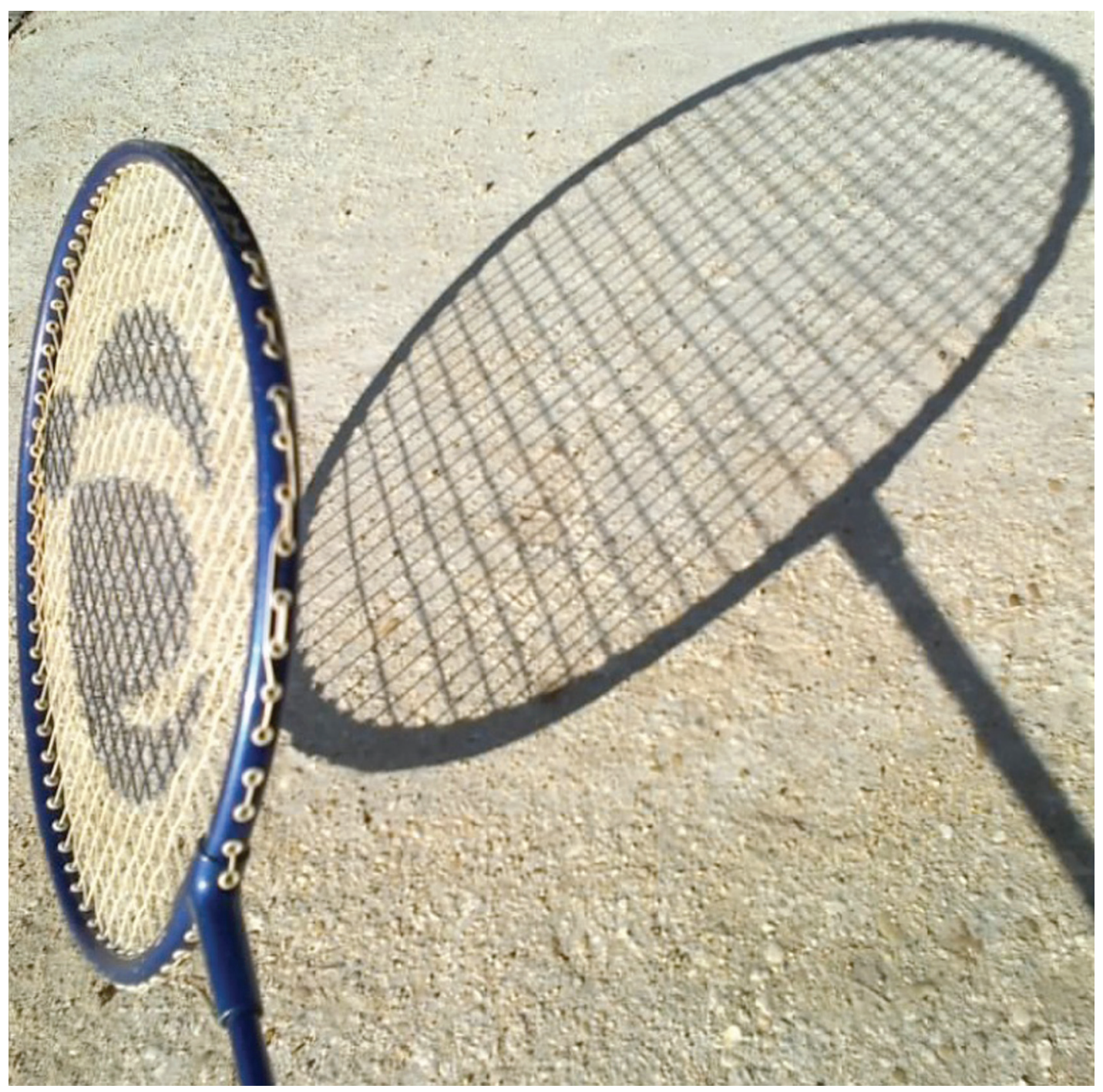

Figure 1. [In colour online, see http://dx.doi.org/1068.p7396] The grey logo is painted on the cords of the badminton racquet. 
It looks as if the shadow of the grey shape on the net is missing. The racquet frame and the cords of the badminton racquet cast their shadows on the surface underneath. But the grey logo does not. The physical explanation is obvious: grey paint is present only on the cords, and not on the spaces between cords. However, owing to colour spreading (see Bressan et al 1997 for a review), the grey region appears to occupy an area which is larger than that occupied by the cords it is painted over, and which includes the holes between cords. We thus experience the whole area as filled with colour, an area in the shape of the logo. The visual system confers object status to the filled shape of the logo. Given its position relative to the cords, if the filled shape of the logo was a physical object, it would bar light and thus cast a filled shadow (an area in the shape of the logo, completely darkened). The fact that we are surprised by the absence of the shadow indicates that we consider the filled grey logo as opaque to light, thus akin to a fully-fledged physical object. Purely visual objects created by colour spreading are expected to behave like any other physical object. In particular, they are expected to block light and to cast shadows.

\section{Reference}

Bressan P, Mingolla E, Spillmann L, Watanabe T, 1997 "Neon color spreading: a review" Perception $261353-1366$ 